\title{
The Impact of Social Media on Traditional Mainstream Media A Case Study of People's Daily
}

\author{
Xuyan Yan ${ }^{1, a}$
}

\author{
Faculty of International Media, Communication University of China, Beijing,100024, China \\ Corresponding author's e-mail: angela@cas-harbour.org
}

\begin{abstract}
The advent of communication technology has posted great challenges to conventional media. The traditional mainstream media are accordingly faced with fierce competition under the flourishing media convergence. People's Daily, as the representative of mainstream media in China, has accomplished media transformation. Within embracing various technologies and engaging with the audience, it earns great attention and credits. By carrying out a case study on the media transition of People's Daily, this research reveals the influence on the storytelling of People's Daily, from content to perspective, and amplifies on how the transition impacts news value. The results of this study indicate that People's Daily wins favor from people by adopting the perspective of the masses, developing audience-focused awareness and labeling itself as an indispensable key opinion leader. Simultaneously, the news value is challenged, as People's Daily presents the audience with brief and emotional content. Accordingly, people could be easily irritated without understanding the whole story and crucial reasons behind the information, besides the tendency of adapting to fragmented information is problematic. Suspicion of unifying public opinions also exists as People's Daily frequently select favorable comments below controversial issues.
\end{abstract}

Keywords: Social media, People's Daily, mainstream media, News media

\section{INTRODUCTION}

With technology advances, China has been through a dramatic revolution in communication. Meanwhile, the popularity of social media especially overturned the way people absorb, digest and spread information. Traditional mainstream media has a tendency to lose control over the previous dominance on agenda-setting. For traditional media, the transition toward melted media can be risky and painful. While many newspapers are struggling with the financial crisis, People's Daily sets up a "Central Kitchen" mechanism to develop its new media products, meanwhile ensures efficiency. As the most influential mainstream media in China, it covers and delivers critical information on its content and tongue. With the adoption of social media, the communication technology brings people closer to the news to educate, inform and entertain [1].

In the view of Marshall McLuhan, the medium is the message [2] and it is the medium that shapes and controls the content and influences public opinions. Most of the time People's Daily conveys similar messages in different ways between social media platforms and the physical newspaper. This essay aims to explore how social media influences People's Daily to represent information differently and how the transition of People's Daily affects the audience and itself.

\section{THE SOCIAL MEDIA AS A NEW ARENA}

Since the emergence of online forums in 1994, followed by the Blogging, Renren and Sina Weibo, local social media took off at an unprecedented pace in China. Owning the world's largest user base - over 800 million [3], China provides a vigorous environment for social media from video websites, short video apps to social-networking sites [4]. It is suggested that the Chinese tend to own accounts on different platforms and spend more than 40 percent of their time online on social media. Thus, the competition is bound to be rather fierce in the arena of social media. The audience is geographically, economically, anthropologically diversified and the diversification is a hindrance for media that wants to reach them all. The complicated structure can block organizations from entering the market and gaining ground.

Presumably, the trend of social media is a challenge for both media and audience all over the world. With information becoming extremely decentralized, people have to develop media literacy to distinguish the messages worth reading. Meanwhile, exactly as the lack of trust of the public that may lead to the social media revolution [5], the possibilities provided for We Media empowers individuals to make their voice, thus the public discussion 
inevitably deducts the authority of mainstream media.[6] Within the social media, individuals and organizations are able to share, recreate, discuss, and modify user-generated content [7], profoundly changing the media landscape. The audience can not only find self-identity and develop cyber-relationship on social media platforms, but also receive the feeling of being present and being heard. They are looking forward to being understood, engaged and responded, rather than simply being informed. Given that, the traditional channel of mainstream media is deeply doubted and the power is simultaneously dissolved. Nonetheless, social media also furnishes journalists with opportunities to engage the audience and re-establish the brand of the newspaper.

The Chinese government is heavily involved in mainstream media and it appoints the media with the responsibility of serving as mouthpieces of the government. It was not until recent decades that diversity and competition were encouraged to better encounter the market and profit from advertisements [8]. Social media provides everyone with a chance to witness and speak, to receive information directly rather than through journalists, enhancing the reliability of news, to a certain extent. Though the government still posts restrictions on media, the mainstream media starts with gathering local information and launching public relations programs to attract readers and avoid bankruptcy.

As the most popular newspaper in China, People's Daily is transforming itself toward a new mainstream Omni-media and media group with over ten platforms and hundreds of terminals, including newspaper, magazines, website, web TV, webcast, electronic board, mobile news, Weibo, and WeChat official accounts. Currently, People's Daily runs 30 branch newspapers and periodicals, 44 websites, 118 Weibo accounts and 31 mobile phone apps. It owns 100 million followers on Weibo, gains ground on WeChat and many other social media platforms. As estimated, the total subscribers have been surpassed 300 million[9].

In 2014, People's Daily developed a "central kitchen style" Omni-media platform to better integrate traditional and new media according to the central government's policies and the vision of development. This working mechanism helps with news planning, gathering, editing and reporting on an organic pace. Then the news would be edited into different forms and released on multiple platforms, thus achieving efficiency.

\section{IMPACT ON THE CONTENT}

Political power plays a crucial role. Despite the flat organizational structure of social media platforms, the hierarchy of message flow yet exists partly due to the political system, which prioritizes the key content to mainstream media such as People's Daily, Xinhua Agency and China Central Television, thus guaranteeing them with popularity, authority and reliability. As the official newspaper of the Central Committee of the Communist Party of China, the People's Daily is undoubtedly government-friendly and shoulders social responsibility for propaganda alongside carrying on news value and commercial profits. Its contents on social media focus on politic and social issues and merely designed to influence the domestic audience in terms of the platforms WeChat, Weibo and Tik Tok mainly target the Chinese users. Besides, away from the literary supplement in the newspaper, it sets a special column "Night Reading” on WeChat to post inspirational articles and encourage the audience to be open-minded and kind.

In order to better communicate with the audience, People's Daily adopts an audience-oriented strategy, which contains developing inviting titles and contents and adjusting the language style from indifferently official to casual and friendly. It does not simply repost articles from newspaper, but edits messages with audios, videos, flash animation and HTML5 animation. More importantly, to bridge the inter-generational discourse gap, it abandons the perspective of grand narratives of patriotism and nationalism. Instead, People's Daily starts to dig the individual discourse expressions and civilian narratives. Expect for concentrating on leadership and the Party, it depicts how ordinary workers suffer tragedies such as Corona Virus and severe earthquake, how the life of citizens is influenced by Two Sessions - National People's Congress (NPC) and the Chinese People's Political Consultative Conference (CPPCC), and how foreigners integrate into Chinese society.

As the introduction on Weibo and WeChat indicates, it intends to participate, communicate and record the era. People's Daily starts to embrace diverse information on social media. Since the state posts strict restrictions on social media dominated by the Western world, such as Twitter, Facebook and YouTube. While people have no access to those platforms, Peoples' Daily translates favorable messages, interesting or significant ones, and shares on domestic media platforms. It shares messages of the unfortunate death of Kobe, the trend of WWIII on Twitter, common knowledge and discussions of FIFA World Cup and how ordinary people react to the war in Iraq. While in the physical newspaper, People's Daily barely mentions international social and cultural topics.

Given that People's Daily is a state-owned media and regulated directly by the Party, the audience could be skeptical of the authority which often covers up the truth to avoid conflicts. Thus, the masses value opinions from Key Opinion Leaders who stand on the side of people. By making critics on social issues and hot topics, People's Daily gradually brands itself as a key opinion leader, reducing the feeling of indifference and maintaining reliability. Praising popular We Media professor, recommending high-quality documentaries, analyzing the female image in domestic TV shows and the reason of popularity of side hustle, criticizing radical social trend of extreme nationalism and consumerism, and judging on uncivil behaviour of celebrities, People's Daily makes comments on different aspects of society from a seemly objective attitude. For much social news nonetheless, especially local news agencies or witnesses, People's Daily would not be the very first to report or upload. But 
the audience still relies on professional agencies to continue with the procedure of fact verification. It no longer holds information, but truth. People especially expect the People's Daily to voice and draw a final conclusion for it would represent the will of authority and even release the tread of following policies.

\section{THE INFLUENCE ON NEWS VALUE}

Given that the component of the audience could be more far-reaching and complex compared to the physical newspaper, contents posted on social media by People's Daily are comparatively superficial and lack in-depth content, following the trend of fragmentation. It is doubted that the habit of covering interesting information instead of hard news could constrain the conversation on deep value and damage investigative journalism [10]. People who adapt to the narrative style of new media would also be satisfied with short messages and give up reading longer paragraphs and understanding issues in a board view.

On social media, to better draw the attention of the audience, the news is released by People's Daily in a subjective way. With the frequent use of exclamatory marks and words such as "significant" and "must-see", individuals are immersed in the emotional flow of communication. Within the form of short videos, the audience is presented with close- up scenes and a sense of presence, which especially strengthen emotions. Since emotions have become a crucial part of news reporting, they serve as frames for issues and tools to guide the audience without notice [11], leading to intensive social emotionalization.

Though it seems like nowadays everyone has a microphone to voice on social media, People's Daily is not yet wide open. While it criticizes the social issues, it would advocate a favorable attitude and then carefully select comments below each post and merely show the positive ones. When people find their viewpoints are not accepted and shared, they would be frustrated and remain silent, forming and exaggerating the tendency of "spiral of silence" [12].

\section{CONCLUSION}

With the People's Daily adjusting its style of storytelling and gaining ground on social media, this mechanism is also questioned by news value - reduces news to short messages, educates audience to agree and drives them with emotion. Attributed to the unprecedented close attention to people's daily life, it wins favor from youth to the elderly. But it remains unknown whether this mechanism would work in the long run while it paraphrases the messages in an inviting tone however remains the official attitude and shoulders propaganda duty. Hence, it is suggested that the mainstream media do some serious soul-searching and accurately feel the pulse of the nation instead of staying relevant through a friendly attitude [13] and creating emotions.

\section{ACKNOWLEDGMENT}

First and foremost, I would like to show my deepest gratitude to my teachers and professors in my university, who have provided me with valuable guidance in every stage of the writing of this thesis. Further, I would like to thank all my friends and roommates for their encouragement and support. Without all their enlightening instruction and impressive kindness, I could not have completed my thesis.

\section{REFERENCES}

[1] M. Brown. Bringing people closer to the news. Brandweek, October 2, 2000, p. 26.

[2] Q. Fiore, M. McLuhan. The medium is the massage. New York: Random House, 1967.

[3] Xinhua Agency. The number of Internet users in China has reached 830 million. 2018. Accessed on 15 Mar. 2020. http://www.gov.cn/xinwen/2019-08/13/content_5421006. htm.

[4] C. Chiu, C. Ip, A. Silverman. Understanding social media in China. April 2012. Accessed on 18 Mar.2020. https://www.mckinsey.com/business-functions/marketingand-sales/our-insights/understanding-social-media-in-chin a\#.

[5] R. A. Harper. The Social Media Revolution: Exploring the Impact on Journalism and News Media Organizations. Inquiries Journal/Student Pulse, 2010, vol. 2, no. 03. pp.1-7

[6] I. Banerjee. The Impact of New Media on Traditional Mainstream Mass Media - A Critical Assessment. A Series of Lectures on Trends \& Future of the Malaysian Mass Media. Presented at Dewan Tunku Canselor, University of Malaya Kuala Lumpur, 2008.

[7] J. H. Kietzmann, K. Hermkens. Social media? Get serious! Understanding the functional building blocks of social media. Business Horizons (Submitted manuscript). 2011, vol. 54, no. 3, pp. 241-251.

[8] A. Esarey. Cornering the Market: State Strategies for Controlling China's Commercial Media". Asian Perspective.2005, vol. 29, no. 2, pp. 37-83. 
[9] Xinhua. Development of china's news media in 2015. 2016-04-29. Accessed on 25 Mar. 2020 http://www.chinadaily.com.cn/china/2016-04/29/content_ 24958859_14.htm。

[10] S. Holtz. The Continuing Need for Professional Journalism. A Shel of my Formal Self. Accredited Business Communicator, 18 May 2009. Accessed on 24 Mar.

http://holtz.com/blog/media/the_continuing_need_for_pro fessional_journalism/2900/

[11] R. L. Nabi. Exploring the Framing Effects of Emotion: Do Discrete Emotions Differentially Influence Information Accessibility, Information Seeking, and Policy Preference. Communication Research, 2003, vol. 30, no. 2, pp. 224-247.

[12] E. Noelle-Neumann. The Spiral of Silence a Theory of Public Opinion. Journal of Communication, 1974, vol. 24 , no. 2, pp. 43-51.

[13] E. Yapp. Malaysia's New Media Gains Credibility Post-Election. Malaysia Explorer, March 16, 2008. 